\title{
Theoretical sampling process in a Straussian Grounded Theory study*
}

\author{
Processo de amostragem teórica em pesquisa de Teoria \\ Fundamentada nos Dados vertente Straussiana \\ Proceso de muestreo teórico en investigación de Teoría Fundamenta vertiente
}

How to cite this article:

Barreto MS, Simon BS, Marquete VF, Souza RR, Girardon-Perlini NMO, Marcon SS. Theoretical sampling process in a Straussian Grounded Theory study. Rev Esc Enferm USP. 2021;55:e20210212. https://doi.org/10.1590/1980-220X-REEUSP-2021-0212

\section{Mayckel da Silva Barreto ${ }^{1}$ \\ Bruna Sodré Simon² \\ Veronica Francisqueti Marquete ${ }^{1}$ \\ Rebeca Rosa de Souza ${ }^{1}$ \\ D Nara Marilene Oliveira \\ Girardon-Perlini ${ }^{3}$ \\ (iD) Sonia Silva Marcon ${ }^{1}$}

*Extracted from the thesis: "Presença da família durante o atendimento emergencial: vivências e percepções de pacientes, familiares e profissionais de saúde", Universidade Estadual de Maringá, 2017.

${ }^{1}$ Universidade Estadual de Maringá, Departamento de Enfermagem, Maringá, PR, Brazil.

${ }^{2}$ Universidade Federal do Pampa, Departamento de Enfermagem, Uruguaiana, RS, Brazil.

${ }^{3}$ Universidade Federal de Santa Maria,

Departamento de Enfermagem,

Santa Maria, RS, Brazil

\begin{abstract}
Objetive: Describing the theoretical sampling process in the development of a Grounded Theory based on the Straussian strand. The objective of the field research, used as an example, was to develop a substantive theory, based on the theoretical framework of Symbolic Interactionism, about the perceptions and experiences of patients, family members, and health professionals regarding the presence of the family during emergency care. Method: In the theoretical sampling, 42 participants were recruited, divided into nine sample groups, constituted based on the constant comparative method. Results: The description of this example allowed to identify how theoretical sampling guided data collection, which occurred through the in-depth study of concepts and the search for answers to questions arising from the data. Final Considerations: It is expected that the readers find subsidies to understand how theoretical sampling is conducted in a Grounded Theory study, based on the Straussian strand, and thus be able to apply it.
\end{abstract}

\section{DESCRIPTORS}

Qualitative Research; Nursing Research; Nursing Methodology Research; Grounded Theory. 


\section{INTRODUCTION}

The Grounded Theory (GT) was developed by the American sociologists Barney Glaser and Anselm Strauss, in the 1960s, to study the process of death in hospital environments ${ }^{(1)}$. The method seeks to build a substantive theory, based on data obtained and analyzed from social research, to better describe, understand, and explain the meaning of the event from the perspective of the people investigated $^{(2)}$.

Since the presentation of the method, different approaches have emerged. In the 1990s, for example, several texts were published defending divergent opinions of their co-creators regarding issues of induction-deduction, data analysis, and theoretical generation ${ }^{(3)}$. In addition, it is highlighted that, in a more recent perspective, GT is inserted in the constructivist paradigms by Charmaz, of postmodern situational analysis by Adele Clarke, and of dimensional analysis by Leonard Schatzman ${ }^{(4)}$.

Despite the different approaches, there is a consensus that GT, excluding the Glasserian strand, is an interpretive style of qualitative research rooted in the post-positivist paradigm, which characterizes it as an inherently complex methodology ${ }^{(5)}$. Specifically in the Straussian strand, post-positivism and Symbolic Interactionism $(\mathrm{SI})^{(4,6)}$ are adopted as characteristics, which reinforces its theoreticalmethodological complexity. Therefore, to ensure rigor in data collection and analysis, as well as in the result achieved, fundamental components shall be addressed ${ }^{(4,7)}$. Among these, the following stand out: theoretical sensitivity; constant comparative method; theoretical sampling; development of memos and diagrams; codification; theoretical data saturation; and identification of the substantive theory ${ }^{(8)}$. Although all components deserve critical analysis, the theoretical sampling is the focus of this article.

Theoretical sampling is characterized as the selection of participants that is not limited to the inclusion criteria initially proposed. It results from the concomitant data collection, coding, and analysis, to decide which new data will be collected and where to find them ${ }^{(6)}$. This way, it is possible to develop the theoretical bases and explore the emerging conceptual categories, testing and explaining the theory as data analysis progresses ${ }^{(6)}$. Therefore, it is not a procedure seeking numerical significance or population representation, but rather the variability to identify patterns of behavior and attitudes ${ }^{(9)}$, as well as to facilitate the testing, development, and improvement of emerging conceptual categories $^{(10)}$, in the search for theoretical completeness ${ }^{(11)}$. It is used in all GT variants, as it is considered a key procedure for theory construction ${ }^{(12)}$.

The process of building a substantive theory requires the interaction between inductions and deductions ${ }^{(6,13)}$. This is necessary to identify empirical instances with the potential to deepen the insights that arise through a rigorous, systematic, and organized data analysis process ${ }^{(12)}$. This process shall take place until the moment when theoretical saturation is identified, which is achieved with the proper use of theoretical sampling. This is because the focus of the method is to achieve the best theoretical explanation of a given concept ${ }^{(14)}$.

It is identified that national ${ }^{(4,8,15)}$ and international ${ }^{(11,16,17)}$ researchers have shed light on the conceptual, methodological, and operational discussions on the application of GT in the field of nursing. However, no publications were identified that discussed, in a particular way, the theoretical sampling process based on the Straussian strand of GT. In addition, literature reviews on the application of this method in nursing research found the need for greater scientific rigor in its use ${ }^{(8,15,18)}$, especially with regard to the iterative process of fieldwork and the theoretical development from theoretical sampling ${ }^{(17)}$.

Classic texts on theoretical sampling in GT are mainly focused on their methodological foundations ${ }^{(6,9,19)}$, and a limited number of books and articles ${ }^{(12,20)}$ was concerned with describing how theoretical sampling occurs in the practical development of GT. Therefore, this study is of significance in providing subsidies, above all, for beginner investigators interested in using GT, as its objective was to describe the theoretical sampling process in the development of a Straussian-based Grounded Theory.

\section{OUTLINING THE METHODOLOGICAL TRAJECTORY}

\section{Design of Study and Ethical Aspects}

This is a theoretical study describing the development process of theoretical sampling in a GT study, whose objective was to develop a substantive theory, based on the IS framework, about the perceptions and experiences of patients, family members, and health professionals of the presence of the family during emergency care. The research followed the ethical precepts provided for in Resolution 466/12 of the National Health Council, and was approved by the Permanent Human Research Ethics Committee of the signatory institution (Opinion: 1.882.37/2017).

\section{DESCRIPTION OF THE LOCAL}

\section{Research Context}

The study setting consisted of the Emergency Room (ER) of two health units, named Unit A and Unit B, which despite being located in two nearby municipalities in the state of Paraná, Brazil, differ in terms of geographic and social coverage of the users population, as well as regarding the physical structure, professional profile, and clinical conditions attended. Unit A only receives patients with clinical illnesses and Unit $B$ is a reference for 30 municipalities, thus seeing severe and complex patients with clinical and traumatic problems. Such configurations allowed variability in the composition of theoretical sampling, which is important for the initial data collection process in GT.

\section{Population}

For the participants selection, the triangulation of informants was performed, who were intentionally defined and formed three initial sample groups consisting of 


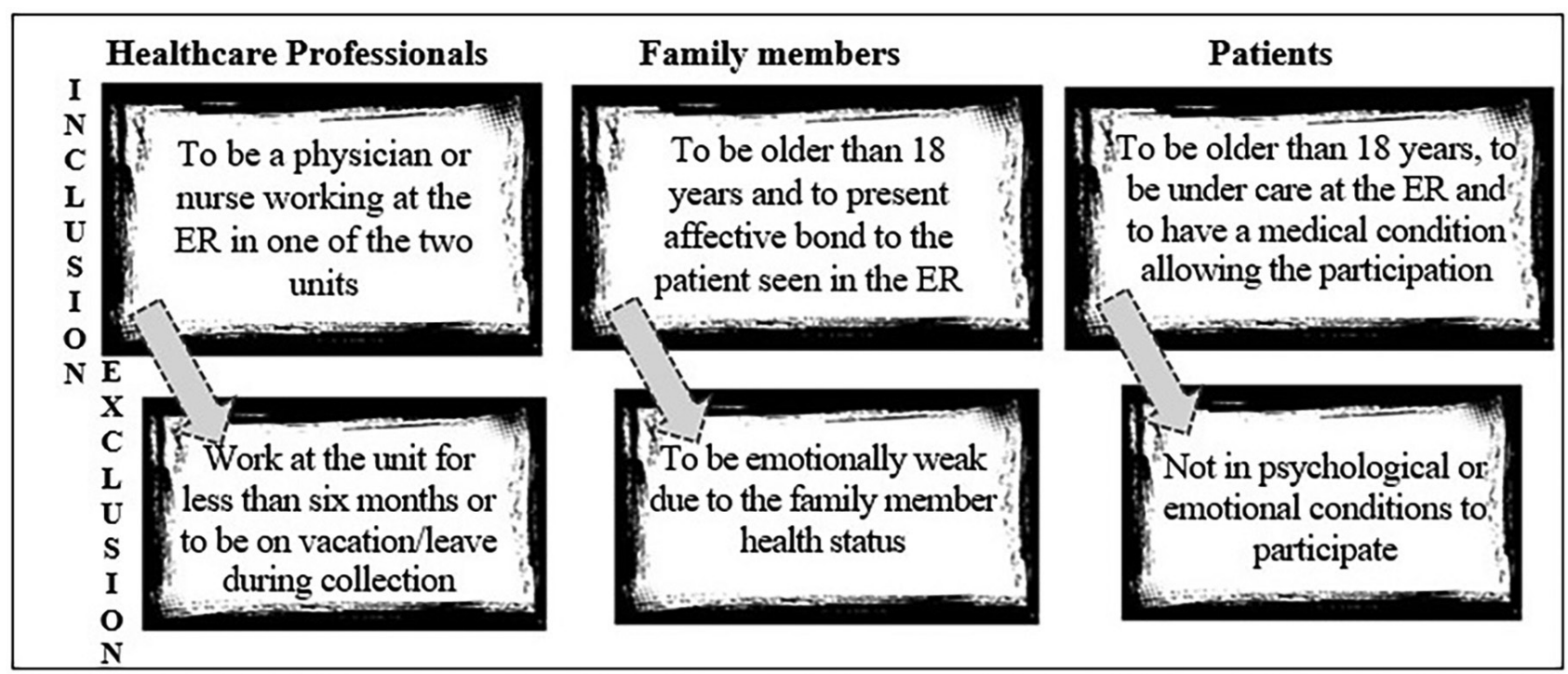

Figure 1 - Inclusion and exclusion criteria initially defined for study participants.

professionals, patients, and family members, according to the established inclusion and exclusion criteria (Figure 1).

\section{DATA COLLECTION PERIOD AND TECHNIQUES USED}

Data collection took place between October 2016 and February 2017, using individual, in-person, audio-recorded interviews, with an average duration of 43 minutes, on the premises of the health services, in a reserved room. The generating question of the initial interviews was: What is your perception in relation to the presence of the family in the ER during the service? The interview script also contained questions about the participants' sociodemographic profile, which was especially useful for "breaking the ice". Subsequently, this information allowed the identification of the participants' social reality and the recognition that each narrative was inserted in its geographical, political, social, economic, and cultural context.

As proposed by the GT, the constant comparative method was used, so that data collection and analysis were concomitant, and the interview script was adjusted throughout the study to contemplate the progressive development, in-depth analysis, and densification of the categories. This aspect of modulation of the collection instrument, based on demands arising from data analysis, is common and relevant for theoretical sampling to take place.

\section{Data Analysis}

In the Straussian strand of GT, the analysis occurs through open, axial, and selective coding ${ }^{(6)}$. The software QDA miner ${ }^{\circledR}$ was used in the coding process.

\section{INTRODUCING THE THEORETICAL SAMPLING PROCESS}

The study was guided by the SI theoretical framework ${ }^{(21)}$. This is because, in addition to this framework forming part of the paradigmatic bases of the Straussian GT, it started from the understanding that the perceptions and experiences of each active actor involved in emergency care (patients, families, and professionals) are part of a process in constant interaction, assigning meanings to experiences through the interaction of self, mind, and society. Based on the interactionist perspective, people act in relation to the actions of others, interpreting the action and acting again, based on the meanings. Thus, SI supported the development of the study and guided the analytical movement carried out in theoretical sampling, from data collection, analysis, and interpretation.

Throughout the research, nine independent sample groups were formed - health professionals, family members, and patients, each constituted three distinct groups (Figure 2). In total, 42 people participated, distributed as follows: 13 patients cared for in the ER, 13 patients' family members, and 16 professionals (eight physicians and eight nurses). It should be noted that the sample groups (for example, G1 of family members, patients and professionals) were not necessarily constituted simultaneously, but this could happen and occurred, especially, in the groups of family members and patients. However, it is emphasized that the groups were independent from each other.

The theoretical sampling process helped in the elaboration of the substantive theory: "The social construction of a conditioned, sporadic and flighty family presence during emergency care", consisting of four categories and 12 subcategories (Figure 3). Next, the theoretical sampling process for groups of health professionals, family members, and patients is described in detail.

\section{Healthcare Professionals}

Data collection with the 1st SG consisting of health professionals was initiated for convenience in Unit A, due to greater ease of access for the researcher. This group consisted 


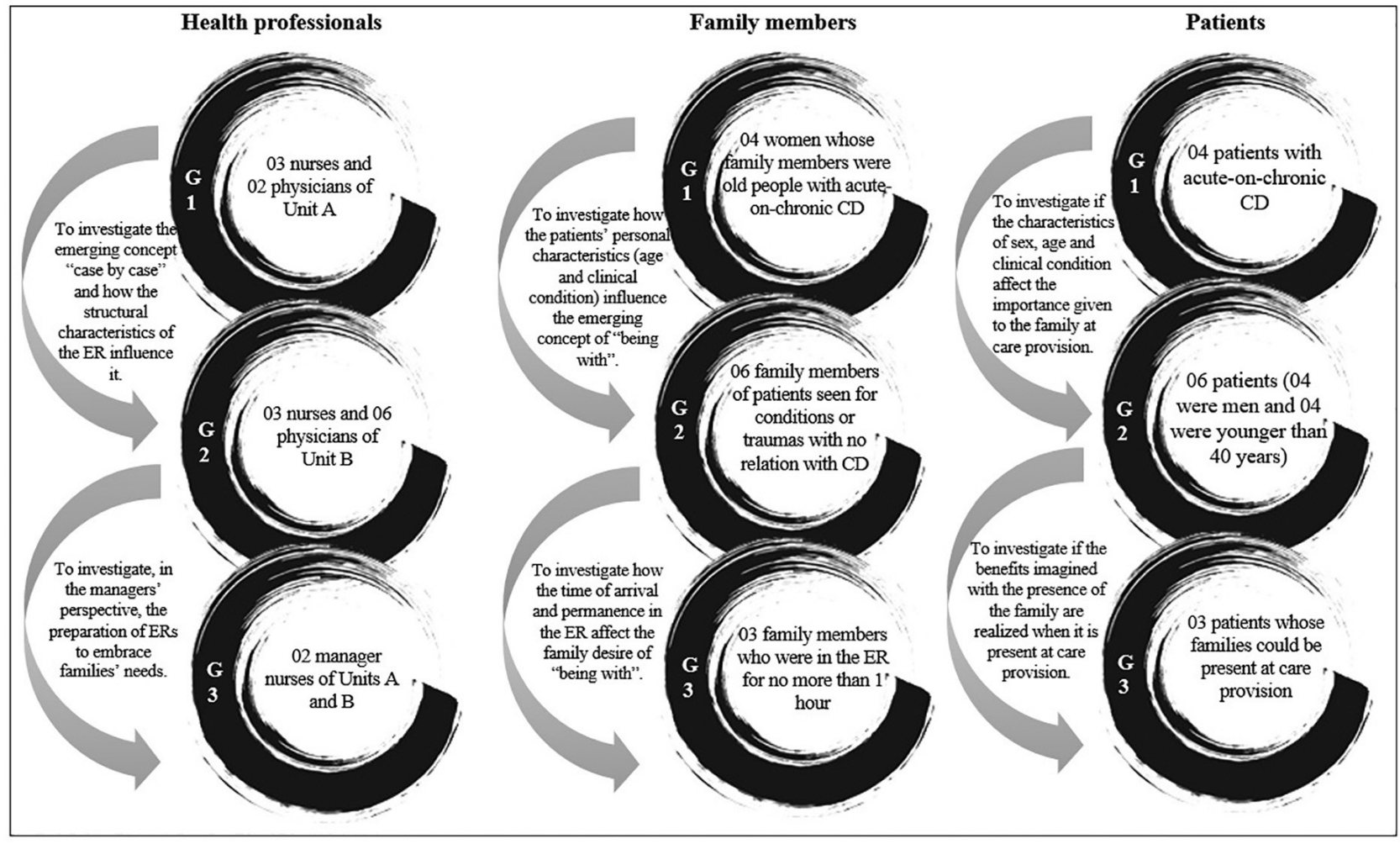

Figure 2 - Representation of the theoretical sampling process and formation of sample groups. CD: Chronic disease; ER: Emergency room. Source: Prepared by the authors.

of five participants - three nurses and two physicians randomly selected from a universe of eight nurses and eight physicians. At the beginning of the codification process, it was identified that, despite the usual pattern of behavior, socially accepted and practiced, being that of not allowing the presence of family in the ER, there were specific cases in which professionals consented, even for brief moments. In this regard, the professionals mentioned that a "case by case" assessment was required (in vivo code), considering different aspects and interactions.

During the axial coding, we sought to identify which factors cooperated to shape the professionals' actions whether to allow the presence of the family. As an explanation given by those who allowed, there was the older age of the patient and the attempt to provide more information to the family. For those who were not allowed, the conceptual code was identified: "Aspects that do not allow the presence of the family", and among the most relevant reasons - as they also appeared as conceptual codes, and not just as provisional codes - there were aspects related to "Lack of physical structure"; "Lack of human resources" and "Lack of medical and hospital equipment and supplies". Thus, considering that the ER environment and context seemed to emerge as influencing aspects of professional decision, it was considered opportune to seek professionals who were inserted in another emergency context, where, it is known, such conditions as structure and material and human resources were distinct, causing them to establish other social interactions within the available physical space.
Therefore, in order to better understand provisional concepts and conceptual codes that were emerging, the formation of the new SG of professionals sought to answer the following questions: a) What do professionals understand by the emerging concept "case by case"? b) Are the concerns about not allowing the family to be present in the $\mathrm{ER}$, concerning the environment, initially characterized as precarious, generalizable, or are they directly related to the social interactions established in this context in which the first interviewees were inserted? If concerns regarding the precariousness of the environment are not evident, c) What other symbolic aspects influence the action of professionals whether to allow the presence of the family in the ER? At that time, the sampling was no longer for convenience and turned to be intentional based on data analysis. Thus, the 2nd SG of professionals consisted of six physicians and three nurses working in the ER of Unit B, randomly selected from a universe of eight nurses and 12 physicians.

Based on the new data obtained, it was possible to saturate codes and initial categories, which revealed that the professionals understood each care situation, patient, family, team, and context of the ER as single and unique and, therefore, they have to be considered in this way when addressing the possibility of families following the care process. Thus, even though professionals from another emergency service, with distinct structural characteristics and work process, were interviewed, it was found that the environment and context - unprepared to receive the families, according to their perceptions - were again interpreted and defined as 


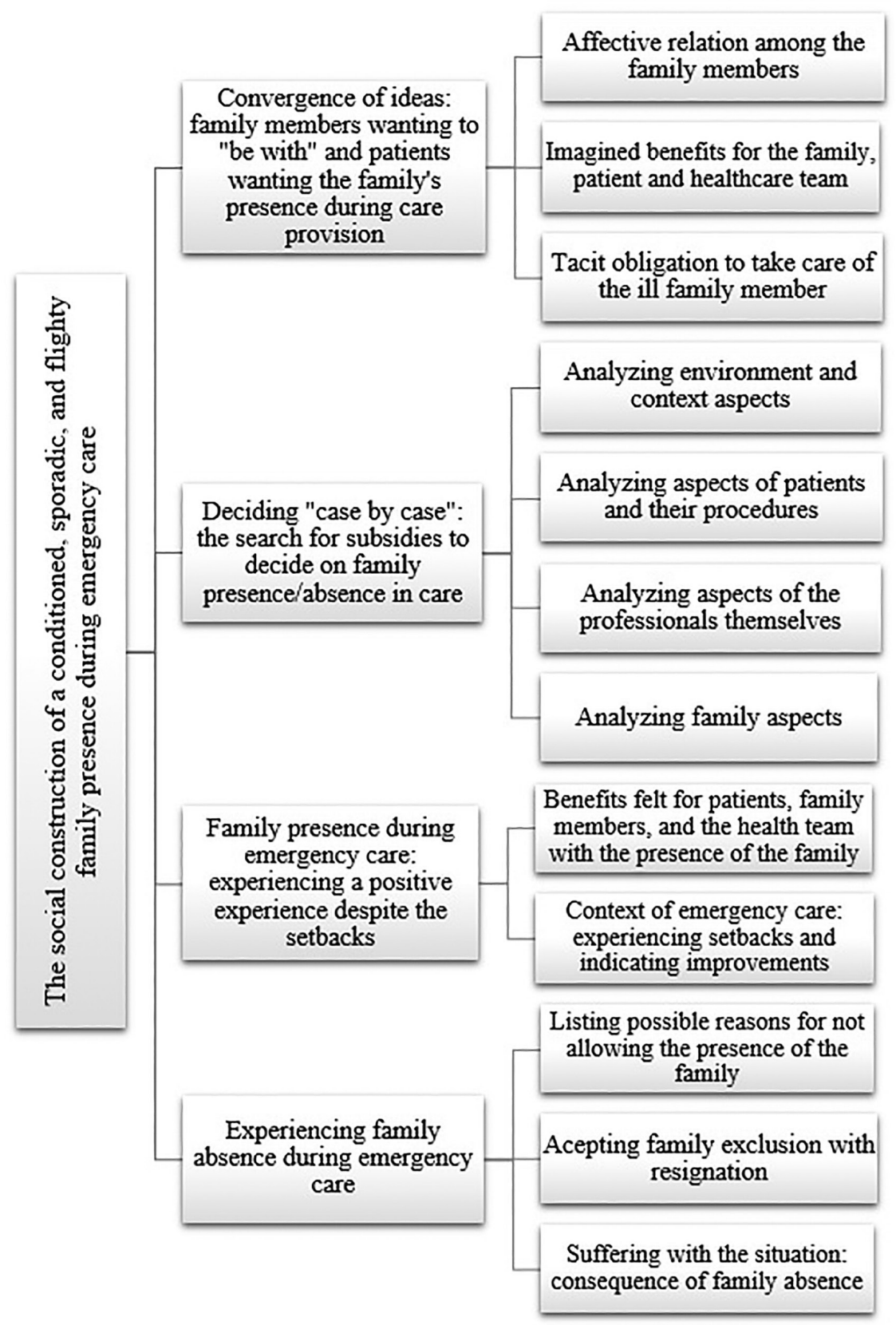

Figure 3 - Representation of the identified substantive theory, its categories, and subcategories.

inadequate, being , therefore, indicators and strong limiters of the decision to allow the presence of families.

Furthermore, other anxieties of professionals were being outlined in the light of data interpretation, such as the patient's medical status and the procedures to be performed; the family's needs and behaviors; and even individual anxieties as a person and health professional, for example, with regard to the fear of misinterpretations by the family, given the professional behavior. At that time, it was possible to progress from the "initial search for new data" to "identifying influences among data" and "establishing connections between categories", which allowed the construction of interrelationships among emerging categories.
Thus, it was necessary to broaden the understanding of the categories that were formed and saturate those already identified and developed. Therefore, it was necessary to discover the meanings the emergency units managers gave to the environment and context, allowing us to identify if, in fact, these were the most relevant to justify the behavior and professional action. The new questions that arose were: a) According to the perception of those who manage the units, are they prepared to embrace and meet the demands of families during emergency care? b) How could the units and their professionals be better prepared to receive the families in the ER during the service? Therefore, the managers of the two units where the study was conducted were interviewed, forming the 3rd SG of professionals. 
Data analysis, using selective coding, allowed us to see that other elements, in addition to the environment and context, were also relevant for the professionals' decision. Based on the understanding of aspects related to service management, regarding the strengths and weaknesses for the effective presence of the family in the ER, it was possible to notice that the professionals fluctuate/oscillate between allowing or not the presence of the family when considering, in this decision, arising from the social interaction established, the "case by case" analysis of aspects concerning the environment and context, the patients and their procedures, the professionals, and the patient's own family.

\section{Familiy Members}

For family members, the $1^{\text {st }} \mathrm{SG}$, selected for convenience of access by the researcher, consisted of four women (a sisterin-law, a sister, a wife, and a daughter) over 50 years old, with low level of education and income, who were in Unit. A. Their family members being attended were elderly people who had acute chronic conditions (i.e., diabetes mellitus - DM, chronic obstructive pulmonary disease, systemic arterial hypertension - SAH, and acquired immunodeficiency syndrome). The contact with them occurred through the identification of patients under care at the ER and later search, at the reception of the unit, for their relatives.

Data open coding demonstrated the conceptual code "Wanting to "be with' my family member in the ER". "Being with", therefore, was another in vivo code identified in the speeches and used in data analysis. Family members showed that, despite trusting the professional performance and characterizing the care received in the ER as adequate, they would like to remain with the patient all the time. This is because they believed that their presence would benefit both the patient and themselves. Data also showed that health care was centered only on the patient, but in the case of the elderly, there was greater flexibility on the part of professionals, allowing families to more easily access the ER.

In addition, one participant revealed that: "the young patient does not need the presence of the family, but for the person who is over 60 years, the company of a family member should be allowed, because the elderly person is more sensitive". Age and chronic conditions seemed to influence this definition and, consequently, the family desire. Given the initial findings, the following questions arose: a) Do family members actually identify this increased sensitivity, which leads to the need for the presence of the family, only in elderly patients with chronic conditions? b) Do family members of young or elderly patients affected by an acute health problem also want to "be with" their loved one in the ER and perceive the same facilities, to make themselves present, compared to family members of elderly people with chronic conditions?

Thus, we sought to establish a new SG that included family members of young or elderly patients, whose reason for seeking emergency services was not directly related to the worsening of chronic conditions. Thus, in the 2nd SG, six family members were interviewed (two aunts, a husband, a wife, a son, and a mother), aged between 35 and
63 years. Family per capita income and the number of years of education were higher compared to the first group. Five of the patients were young or adult and one was an elderly, and all had acute health problems (i.e., acute peritonitis; intestinal volvulus with loop rupture; motorcycle accident; bicycle accident with spleen rupture; drowning; and attempted suicide).

Initially, the variability of the participants' sociodemographic characteristics, as well as the reason for entering the ER by the family patient were considered as relevant, in an attempt to provide greater versatility to the collected data. However, as theory development progressed, it was considered important that theoretical sampling be conducted to adjust and refine the emerging substantive theory.

Based on the constant comparative method, it was found that the need to "be with" the loved one remained among family members, regardless of whether the patient was young or elderly without chronic conditions, as the meaning of presence, apprehended in family interactions, refers to the bonds of union that have to be preserved, regardless of the clinical condition and stage of family development.

Until that moment, it had been possible to observe that the family members perceived access restriction to the ER with resignation and understood that little could be done to change this scenario. Possibly, as all patients had been in the service for at least 24 hours - there was even the case of a patient who even after undergoing an abdominal surgery returned to the ER, while waiting for hospitalization - the family members had already tried to overcome the perceived barriers to be present in the ER, with little or no success, which led to resignation.

Therefore, a question arose about the "time" factor, as in situations of prolonged stay in the emergency service, family members showed less anxiety and greater familiarity with the environment. This is due to the fact that visits to the unit and meetings with health professionals had already occurred on a few occasions or, specifically, in the case of the mother of a 17-year-old patient, who could be with her child full time, the social interaction established with the patient and professionals was constant.

In this perspective, the following questions arose: a) Are the needs for information and for being able to "be with" the loved one in the ER influenced by the patient's arrival time at the emergency unit? b) What strategic actions did family members employ/would employ to "be with" their loved one in the ER? Such questions led the researchers to interview family members of patients who had been admitted to the unit at most an hour before, to investigate how they were giving meaning and experiencing the immediacy of the situation of acute and severe illness of their relative and if this influenced their desire to be in the ER and the strategies used to achieve this.

The search for family members with these characteristics made data collection a little difficult, as it was necessary for the new participants to experience a particular aspect of the phenomenon related to the time elapsed between the patient's arrival at the emergency service and the completion of the interview, demanding more time to locate potential 
participants of the 3rd SG. Three family members participated in this group (a son, a wife, and a niece - raised as a daughter by her uncles). Age ranged from 29 to 45 years and education from four to 12 years of study. In the three cases, the patients were over 54 years old and had chronic conditions (SAH and/or DM), and the search for the unit was due to the worsening or exacerbation of the underlying illnesses.

The selective coding allowed us to identify that, in this SG, the meanings attributed pointed to an even more difficult experience in the first hours after the family member's entry into the ER, as the anguish and fear were more latent, and the need for information about the patient and the desire to "be with" were more notorious. As for the strategies they used to "be with" the family member, it was noticed that they did not differ from those pointed out by the other interviewees, as the feeling of powerlessness in the face of exclusion from the ER was perceived in the same way as for other family members, demonstrating the theoretical saturation of the data for this group.

\section{Patients}

In the case of the 1 st $\mathrm{SG}$, selected for convenience of ease of access and, especially, limited by the physical and/or emotional impossibility of communication with the researcher by many potential participants, it consisted of four elderly women being attended at Unit A, with no employment relation, low level of education, and low family income. The constant comparative method allowed us to identify that they would like to have had the presence of a family member during the service, as they considered the family important in times of illness and their entry into the ER would bring benefits to the family-patient-professional triad.

Based on this, questions arose regarding the importance given to the family during an episode of illness/acute illness and whether the need for their presence during care provision would be limited to the perception of elderly women or whether they would be generalizable and extendable to other patient profiles. Trying to answer these questions, a SG consisting of young and/or male patients was formed, since aspects related to age and sex could be symbolically related to the provisional concepts and conceptual codes identified.

Therefore, the 2nd SG consisted of six patients (four men), aged between 23 and 66 years, four of whom were under 40 years of age. The new findings allowed us to condense the emerging categories emerging in the 1 st SG, revealing that patients longed for the presence of their families, because they identified benefits for themselves, as well as for their families and the professionals. However, when the level of abstraction was raised, it was identified that none of the patients interviewed had actually experienced the presence of the family during the service, causing the speeches to be circumscribed to the idealization plane and anchored in the imagined benefits, but actually rooted in the meanings of family exclusion.

Thus, the questions arose: a) Did patients who had family members as companions, at least in part, in the emergency care, identify the realization of the imagined benefits? b) What are the experiences and meanings attributed by patients to the experience of having a family member in the ER during care? These questions gave rise to the 3rd SG, consisting of three individuals whose families were able to be present during care. Based on the selective coding, this allowed to expand, densify, and saturate the categories identified in previous stages of theoretical sampling, confirming the understanding that benefits with family presence materialized when it actually happened. The identified benefits were: offering greater safety and physical and emotional comfort to patients; as well as a reduction in the suffering of family members, because they were able to clarify doubts and ascertain that the patient received assistance in a comprehensive and qualified manner. Professionals benefited from the possibility of obtaining more information about the patient's past medical history and current health problem, facilitating care.

\section{COMPARING AND DISCUSSING WITH THE LITERATURE}

This theoretical study describes how theoretical sampling was used to conduct a GT study on the perceptions and experiences of health professionals, family members, and patients regarding the presence of the family during emergency care. In this example, the strategies used were a) adding new participants and b) expanding/modifying data collection instruments, which allowed the researcher freedom to define the participants, considering the experiences they had with the phenomenon under investigation, and even to (re)define the type of environment and the techniques to produce data collection.

Theoretical sampling can be performed in three main ways, at different stages of a GT research project, namely: a) from the addition of new participants with a set of particular characteristics and theoretical considerations that the researcher considers relevant to data expansion; b) progressing through a variety of techniques applied in data collection, and c) performed within the data already collected, that is, when the data set is approached again for a secondary analysis ${ }^{(12)}$.

In the different groups of participants (professionals, family members, and patients) data collection was initiated through convenience sampling. This strategy is described as useful for selecting the first (one or more) participants that are accessible to investigators at that point in the research. Then, we moved to intentional and theoretical sampling, to select participants who could help in the densification of the emerging conceptual categories and in the development of substantive theory, with the focus being directed towards the generation of data that would meet the need for filling in the analysis gaps. This path was consistent with what is proposed in the literature ${ }^{(20)}$, which points out that sampling in SG changes from convenience to intentional and theoretical when the investigation focuses on the construction and/or development of the substantive theory.

Other authors ${ }^{(6,19)}$ point out that theoretical sampling starts at the point where researchers focus on finding patterns and processes in the data and, therefore, question 
their data about "what is happening here?". When questioning the data, aiming to use theoretical sampling, researchers are exercising theoretical sensitivity, which refers to the ability to have insights, to make sense of the data, separating what is pertinent from what is not ${ }^{(9)}$. Moreover, theoretical sensitivity is understood as the ability based on the knowledge acquired by the researcher from scientific literature, academic, professional, personal experience and, mainly, expertise with the nuances of the analytical process in $\mathrm{GT}^{(6)}$.

The methods and tools listed by the researchers helped in the search for an answer to the study questions. However, it is essential that the person who collects and analyzes data from the perspective of GT has a keen eye and a keen ear to recognize the insights. From then on, to be able to generate, extract, refine, intensify, and make sense of the data collected through the participants' narratives and the analytical observations conducted by the researcher ${ }^{(22)}$.

Another point that is important for the development of sampling is the fact that the researcher remains close to the data during coding ${ }^{(6)}$. It is known that the GT method is based on data collected, coded, and analyzed, and the use of in vivo codes is a strategy that can collaborate to keep the researcher close to the data. It should be noted that the in vivo codes are configured as specific terms or commonly used by the participants ${ }^{(19)}$, functioning as markers of the narrative and of the meanings attributed to the experience. In this study, using these codes ("case by case" and "being with") allowed to keep attention to what the data showed.

The completion of theoretical sampling, in this research example, occurred when no theoretical gaps to be answered with the expansion of the sampling were found as the analyses of all the different sample groups were integrated into the paradigmatic model, that is, theoretical saturation was reached. To testify the reach of saturation, the validation process of the substantive theory was carried out, which took place with four health professionals, two family members, and two patients, who had not participated in the previous interviews.

The literature ${ }^{(6)}$ highlights that GT researchers, in the Straussian strand, reach theoretical saturation when they seek more data during theoretical sampling, but do not find new properties or dimensions in their categories, and the paradigmatic model is properly identified. Theoretical sampling and theoretical saturation basically depend on the search for the iterative process and the detailed verification of the categories constructed in relation to the data obtained, which ideally should be done through the construct validation process ${ }^{(3)}$.
In this respect, different authors have described that theoretical sampling comes to an end when the researcher realizes that he/she has completely interrogated the conceptual dimensions inherent to the phenomenon investigated ${ }^{(6,12)}$. That is, sampling shall only be stopped when concepts and substantive theory are well saturated and become comprehensive, presenting a high explanatory power, allowing theoretical transfer, that is, applicability to contexts beyond the one studied ${ }^{(20)}$.

It is worth considering that the concern with the principles of objectivity, validity, reliability, confirmability, and replicability in qualitative research still permeates academic discussions. Although quality is crucial in qualitative research, the criteria that validate it still remain obscure and uncertain ${ }^{(3)}$. Specifically in GT, it is believed that the use of theoretical sampling to guide data collection, promote the understanding of concepts and meanings, reach theoretical saturation, and develop a substantive theory, as well as a complete and clear description of this sampling process in the research reports published are strategies that provide greater scientific rigor and quality to research.

The limitation of this study is that it presents only one example of GT research, which possibly circumscribes the reader's understanding. However, considering the limitation in the length of scientific articles, it was decided that more details of a single example would be presented, compared to the possibility of presenting several superficial examples, which would leave important gaps for the reader's understanding.

\section{FINAL CONSIDERATIONS}

This theoretical study sought to describe the development process of theoretical sampling in a GT in the Straussian strand. With the detailed description of the conformation of nine sample groups and the strategies employed for their development, it is hoped that readers will find subsidies to understand how theoretical sampling is conducted in a GT study and, consequently, to apply it. It is essential that researchers, when using GT, understand the essential characteristics of the method. This way, the studies developed can produce increasingly dense data that, in fact, portray the reality of people facing the phenomena under investigation. Finally, it is important to highlight the importance of aspects that clearly describe the theoretical sampling in published research reports.

\section{RESUMO}

Objetivo: Descrever o processo de amostragem teórica no desenvolvimento de uma Teoria Fundamentada nos Dados na vertente Straussiana. O objetivo da pesquisa de campo, empregada como exemplo, foi elaborar uma teoria substantiva, fundamentada no referencial teórico do Interacionismo Simbólico, acerca das percepções e vivências de pacientes, familiares e profissionais de saúde relativas à presença da família durante o atendimento emergencial. Método: $\mathrm{Na}$ amostragem teórica foram recrutados 42 participantes, divididos em nove grupos amostrais, constituídos a partir do método comparativo constante. Resultados: Com a descrição deste exemplo, foi possível identificar como a amostragem teórica direcionou a coleta de dados, o que ocorreu por meio do aprofundamento de conceitos e da busca de respostas para questões provenientes dos dados. Considerações finais: Espera-se que os leitores encontrem subsídios para compreender o modo como a amostragem teórica é conduzida em um estudo de Teoria Fundamentada nos Dados, vertente Straussiana, e assim possam aplicá-la.

\section{DESCRITORES}

Pesquisa Qualitativa; Pesquisa em Enfermagem; Pesquisa Metodológica em Enfermagem; Teoria Fundamentada. 


\section{RESUMEN}

Objetivo: Describir el proceso de muestreo teórico en el desarrollo de una Teoría Fundamenta en la vertiente Straussiana. El objetivo de la investigación de campo, empleada como ejemplo, fue elaborar una teoría sustantiva, con fundamentación en el referencial teórico del Interaccionismo Simbólico, acerca de las percepciones y vivencias de paciente, familiares y profesionales de salud relativas a la presencia de la familia durante el atendimiento de urgencias. Método: En el muestreo teórico fueron seleccionados 42 participantes, divididos en nueve grupos, constituidos a partir del método comparativo constante. Resultados: Con la descripción de este ejemplo, fue posible identificar como el muestreo teórico direccionó la recogida de datos, lo que ocurrió por medio de la profundización de conceptos y de la búsqueda de respuestas para cuestiones provenientes de los datos. Consideraciones finales: Se espera que los lectores encuentren subsidios para comprender el modo como el muestreo teórico se conduce en un estudio de Teoría Fundamentada, vertiente Straussiana y, luego, puedan aplicarla.

\section{DESCRIPTORES}

Investigación Cualitativa; Investigación en Enfermería; Investigación Metodológica en Enfermería; Teoría Fundamentada.

\section{REFERENCES}

1. Glaser BG, Strauss AL. The discovery of Grounded theory: Strategies for qualitative research. New York: Aldine Publishing; 1967.

2. Rieger KL. Discriminating among grounded theory approaches. Nurs Inq. 2019;26(1):e12261. DOI: https://doi.org/10.1111/nin.12261.

3. Charmaz K, Thornberg R. The pursuit of quality in grounded theory. Qual Res Psychol. 2021;18(3):305-27. DOI: https://doi.org/10.108 0/14780887.2020.1780357.

4. Santos JLG, Cunha KS, Adamy EK, Backes MTS, Leite JL, Sousa FGM. Data analysis: comparison between the different methodological perspectives of the Grounded Theory. Rev Esc Enferm USP. 2018;52:e03303. DOI: http://dx.doi.org/10.1590/S1980-220X2017021803303

5. Tie YC, Birks M, Francis K. Grounded theory research: A design framework for novice researchers. SAGE Open Med. 2019;7(1):1-8. DOI: https://doi.org/10.1177/2050312118822927.

6. Corbin JM, Strauss A. Basics of qualitative research: Techniques and procedures for developing Grounded Theory. Thousand Oaks: Sage; 2014.

7. Achora S, Matua GA. Essential methodological considerations when using grounded theory Nurse Res. 2016;23(6):31-6. DOI: https://doi. org/10.7748/nr.2016.e1409.

8. Barreto MS, Garcia-Vivar C, Marcon SS. Methodological quality of Grounded Theory research with families living with chronic illness. Int J Africa Nurs Sci. 2018;8:14-22. DOI: https://doi.org/10.1016/j.ijans.2018.01.001.

9. Glaser BG. Theoretical sensitive: Advances in the methodology of Grounded Theory. San Francisco: University of California; 1978.

10. Charmaz K. Teaching theory construction with initial Grounded Theory tools: A reflection on lessons and learning. Qual Health Res. 2015;25(12):1610-22. DOI: https://doi.org/10.1177/1049732315613982.

11. Currie K. Using Survey data to assist theoretical sampling in grounded theory research. Nurse Res. 2009;17(1):24-33. DOI: https://doi. org/10.7748/nr2009.10.17.1.24.c7336

12. Conlon C, Timonen V, Elliott-O'Dare C, O'Keeffe S, Foley G. Confused about theoretical sampling? Engaging theoretical sampling in diverse Grounded Theory studies. Qual Health Res. 2020;30(6):947-59. DOI: https://doi.org/10.1177/1049732319899139.

13. Santos JLG, Erdmann AL, Sousa FGM, Lanzoni GMM, Melo ALSF, Leite JL. Methodological perspectives in the use of Grounded Theory in nursing and health research. Esc Anna Nery. 2016;20(3):e20160056.

14. Saunders B, Sim J, Kingstone T, Baker S, Waterfield J, Bartlam B, et al. Saturation in qualitative research: Exploring its conceptualization and operationalization. Qual Quant. 2018;52(4):1893-907. DOI: https://doi.org/10.1007/s11135-017-0574-8

15. Peiter CC, Santos JLG, Kahl C, Copelli FHS, Cunha KS, Lacerda MR. Grounded Theory: use in scientific articles published in Brazilian nursing journals with Qualis A classification. Texto \& Contexto - Enfermagem. 2020;29:e20180177. DOI: http://dx.doi.org/10.1590/1980265x-tce-2018-0177.

16. Lewis LF. Putting 'quality' in qualitative research: a guide to Grounded Theory for mental health nurses. J Psychiatr Ment Health Nurs. 2015;22(10):821-8. DOI: http://dx.doi.org/10.1111/jpm.12270.

17. McCrae N, Purssell E. Is it really theoretical? A review of sampling in Grounded Theory studies in nursing journals. J Adv Nurs. 2016;72(10):2284-93. DOI: https://doi.org/10.1111/jan.12986.

18. Girardon-Perlini NMO, Simon BS, Lacerda MR. Grounded Theory methodological aspects in Brazilian nursing thesis. Rev Bras Enferm. 2020;73(6):e20190274. DOI: http://dx.doi.org/10.1590/0034-7167-2019-0274.

19. Charmaz, K. Constructing Grounded Theory. $2^{\text {nd }}$ ed. London: Sage; 2014.

20. Bryant A, Charmaz K. The SAGE handbook of current developments in Grounded Theory. London: Sage; 2019.

21. Blumer H. Symbolic Interactionism: perspective and method. Los Angeles: University of California Press; 1986.

22. Prigol EL, Behrens MA. Grounded Theory: methodology applied in education research. Educ Real. 2019;44(3):e84611. DOI: https://doi. org/10.1590/2175-623684611.

Financial support

Coordenação de Aperfeiçoamento de Pessoal de Nível Superior - Brazil (CAPES) Financing Code - 001 - Process number: 99999.003873/2015-03. 